\title{
WOMEN'S PERCEPTIONS ABOUT QUALITY OF MATERNITY CARE AT TERTIARY CARE HOSPITAL KARACHI, PAKISTAN
}

\author{
Afifa Munawar ${ }^{1}$, Zafeer UI Hassan², Aqeela Ayub ${ }^{3}$, Babar Tasneem Shaikh ${ }^{4}$, Nazeer Ali Buriro ${ }^{5}$, Faheem \\ Ahmed $^{6}$, Ramesh Kumar
}

${ }^{1}$ Nursing Supervisor Jinnah post Graduated Medical Centre Karachi

${ }^{2} \mathrm{SMO} T H Q$ Kotli Sattian

${ }^{3}$ Assistant Professor, children's hospital, Pakistan Institute of Medical Sciences (PIMS), SZABMU, Islamabad,

Pakistan.

${ }^{4}$ Associate Professor Health Services Academy Islamabad

${ }^{5}$ Lecturer Nursing at BINACHS, SMBB Medical University Larkana

${ }^{6}$ Staff Nurse TB Hospital Khairpur-Sindh

${ }^{7}$ Assistant Professor Health Services Academy Islamabad

Correspondence: Afifa Munawar, Cell: +923332067763, E-mail: afifa.baloch@yahoo.com

\begin{abstract}
Background: Each day, around 800 women deaths occur worldwide from preventable causes related to childbirth and pregnancy. Pakistan is one of the countries with a high share of this burden. The Pakistan Demographic Health Survey 2006-7 estimates for maternal mortality ratio was 276 per 100,000. The study is aimed to establish women's perceptions about quality of maternity care in Tertiary care hospital, Karachi, Pakistan.

Methods: A cross sectional mixed method study conducted including 100 post delivered women in the obstetrical ward at tertiary care Karachi, Pakistan. A pre-structured questionnaire was used to collect both qualitative and quantitative data. Participants were interviewed after taking the written consent. Both qualitative and quantitative findings were triangulated and analyzed as per objective.

Results: Overall incidence of disrespect is $56.5 \%$, more than $52.0 \%$ participants subjectively reported feeling humiliated. $40 \%$ percent of the respondents assumed the impolite behavior and rude facial expression of health professional during conversation. Most of the participants said about low quality of care, disrespectful and abusive care at labour room however some of them were optimistic about maternal care in the hospital.

Conclusion: The study concluded that disrespect and physical abuse was common barrier to utilization of services that ultimately effecting on the quality at the tertiary health care facility.
\end{abstract}

Keywords: Delivery, quality of care, violence in health, women's health.

\section{Introduction}

Around $99 \%$ women deaths have been reported in developing countries due to preventable causes related to childbirth and pregnancy. Maternal mortality rate of 276 deaths per 100,000 live births, Pakistan is one of the countries with a high share of this burden. As an intervention for the Sustainable Development Goals 3, the World Health Organization (WHO) strongly suggests that skilled care before, during, and after childbirth can save the lives of women and newborn babies. This can be decrease in the mortality and morbidity rates in the country (1). It has explored that there are many ways to fulfill the intervention about to support the respectful and non abusive service for both mother and child. It has explored indication for perspective contributors to disrespect and violence on individual and society, act and rules, leadership and governance, health care delivery and source factors (2).

Health care workers need training in authentic communication with patients that include mutual agreement and treatment decision decisions and recognition that patients are eventually responsible for their moral decision and their own lives. Accredited facilities should also take responsibility for ensuring that professional in health-care facilities used for practical training are respectful to patients (3). It is the highest challenges of maternal mortality in Pakistan and developing counties. Maternal and child health facility are mage closer to the community although the service of utilization and rate of normal deliveries are remaining poor for the reason that absence of respectful maternity care is alleges to have contributed to consumption of hospital delivery services. In 2013, an estimated 289,000 women died worldwide, down from 523,000 in 1990. But 800 women a day are still dying from complications in pregnancy and childbirth globallyequivalent to 33 an hour (4). Unfortunately, several developing countries 
including Pakistan did not achieve the desired MDG goals on maternal and child health by 2015.Maternal mortality ratio targeted was 140 maternal deaths per 100,000 live births by 2015 . The MMR was 276 per 100,000 in 2006-7. It leads to terrible state of maternal health care and women rights. (5) Good quality of maternal care during pregnancy child birth and postnatal care stage is safe motherhood, to secure the health of child and mother is an appropriate care during childbirth is importance which reduces the morbidity and mortality ratio of both mother and babies (6). There are unreliable reports and rising qualitative evidence that some women experience disrespectful or abusive treatment at the hands of health providers in facilities during labor and delivery, disrespectful treatment may be due to absent or inadequate national human rights policies and their enforcement, lack of leadership in the health system, poor standards of care in facilities, provider demoralization and shortages. It is assessed the frequency of disrespect and abusive experiences as reported by women during facility childbirth (7). Disrespect and abuse can discourage women from delivering their infants in facilities with skilled birth attendants (8). Despite many efforts to decline the rate of maternal mortality, women continued to die during childbirth. Particularly the North Atlantic Autonomous Region (RAAN), possesses extremely high rates of maternal death. It has been suggested that promoting delivery in hospital is an effective process to decrease maternal mortality through providing necessary obstetric and emergency obstetric care to the most women. A significant obstacle to increasing rates of facility-based birth globally is neglect of women patients in health care settings (9). The study is aimed to increase utilization of public health facility for normal deliveries and enhance concept of respectful delivery among mothers and also to assess the perception of respectful care, during and after the childbirth and explain the different categories of disrespect of labouring women

\section{Methodology}

Mixed method cross sectional designed involved both Quantitative and qualitative approach was adopted during this study. Pre-structured questionnaires were used for quantitative and semi-structured face-to-face interviews for used for qualitative part. The study was conducted at tertiary care setting, Jinnah post graduate medical center Karachi Pakistan December 2016. Total 106 women were interviewed by calculating proper sample size. Post delivered Mothers were visited and sought care from obstetric ward and postnatal ward of Jinnah Postgraduate Medical Center Karachi through simple random selection of participants with equal probably among daily admitted. Puerperal sepsis women, intrauterine death and miscarriage women who delivered through cesarean section or have adverse pregnancy outcomes like post Eclampsia were excluded Data were collected through pre structure questionnaire and in-depth interviewed after written consent of participant; the pretested and piloted questionnaires were distributed to mothers and collected individually with the help of trained female data collector. Data collection tool was DeVellis RF. Scale development: theory and applications. 2nd ed. Thousand Oaks, California, USA: Sage; 2003. The question guide was developed for IDI that includes disrespect and abuse free care which has further probing like, physical Harm, none consented care, Non confidential care, Non dignified care, discriminatory care, abandonment care and demand for bribe. Data was analyzed by using the software statistical package IBM SPSS version 21 and frequencies, percentages with cross tabulation between outcome and explanatory variables were calculated. The research and ethical Board of the health services Academy Islamabad ethically approved this research study.

\section{Results}

Socio-demographic characteristics can be seen in Table-1. Results from binary logistic regression models shows of age wise dissatisfaction during delivery, low maternal quality of care for delivery regarding household income and stay in hospital and intention to deliver next child at the same facility from survey respondents from tertiary care hospital 2106.

Table-1: Socio-demographic characteristics of the respondents

\begin{tabular}{|l|l|l|l|}
\hline \multicolumn{2}{|l|}{ Socio-Demographic Variables } & Frequency & Percentage \\
\hline \multirow{4}{*}{ Age } & $<20$ Years & 3 & 3.0 \\
\cline { 2 - 4 } & $21-35$ Years & 67 & 67.0 \\
\cline { 2 - 4 } & $36-45$ Years & 30 & 30.0 \\
\hline $\begin{array}{l}\text { Occupation of the } \\
\text { participant }\end{array}$ & House wife & 83 & 83.0 \\
\cline { 2 - 4 } & Job & 17 & 17.0 \\
\hline $\begin{array}{l}\text { Average income of the } \\
\text { household }\end{array}$ & $<10,000$ & 21 & 21.0 \\
\cline { 2 - 4 } & $11000-15000$ & 61 & 61.0 \\
\cline { 2 - 4 } & $16000-20000$ & 18 & 18.0 \\
\hline \multirow{2}{*}{$\begin{array}{l}\text { Hength of stay in } \\
\text { Hosital }\end{array}$} & $>12$ hours & 70 & 30.0 \\
\hline Participants & $>12$ hours & 30 & 22.0 \\
\cline { 2 - 4 } & Not Educated & 22 & 37.0 \\
\cline { 2 - 4 } & Mrimary & 37 & 32.0 \\
\cline { 2 - 4 } & Middle & 32 & 6.0 \\
\cline { 2 - 4 } & Matric & 6 & 3.0 \\
\cline { 2 - 4 } & $>$ Matric & 3 & \\
\hline
\end{tabular}

We have approached 106 women who was under normal delivery in hospital 96 women were agree to participate in the study. Binary logistic regression models showed of age wise dissatisfaction during delivery, low maternal quality of care for delivery regarding household income, stay in hospital and education of participants. Data was analysis with different categories of low quality care with disrespect variable it shows women who are illiterate and low income status have more suffer with bad attitude and disrespect during their delivery Table-2. One participant said that health professional supposed I am not human being and senseless as their attitude and behavior are humiliated and very poor, caregiver says when you are 
near to death, your relatives bought in hospital why are not before when you were little sick. once time my caregiver said that put down your trouser that I was not able to do it because of much lethargy and she slapped on my legs and abuse me in many ways nevertheless my family members were out of hospital to arrange blood for my transfusion, care taker shouted me that none of your relatives is out for purchasing the medicines. No medicines are available in the hospital. MY has reported that health care provider did not introduce herself and she called me as a "BIBI" never called me by my name and she did not give me information neither the progress of labor nor the procedure and baby. MY described that she has waited long time almost 40 minutes no one came to look at me when my mother called them twice then subsequent to that they come and do checkup and I asked about the discrimination related attribute low socio-economic status and low level of education then she said that yes I have faced a lot of troubles during the child birth and feel much disrespect .I will prefer home delivery as compare to hospital as I got much regard while delivery a baby at home -in the hospital we just got disrespect and abuse from health care providers.

Table-2: Proportion of women who suffered the disrespect during labor

\begin{tabular}{|c|c|c|c|}
\hline \multirow[t]{2}{*}{ Age of the Participants } & \multicolumn{3}{|c|}{$\begin{array}{l}\text { Health provider treated you during } \\
\text { labour or childbirth in respe ctful } \\
\text { way }\end{array}$} \\
\hline & Yes & No & \multirow[t]{3}{*}{$\mathrm{p}$ value } \\
\hline$<20$ years age of the participant & $\begin{array}{ll}1 \\
33.3 \%\end{array}$ & $\begin{array}{l}2 \\
67.7 \%\end{array}$ & \\
\hline 21-35years age of the participant & $\begin{array}{l}38 \\
56.7 \%\end{array}$ & $\begin{array}{l}29 \\
43.3 \%\end{array}$ & \\
\hline $36-45 y e a r s$ age of the participant & $\begin{array}{l}13 \\
43.3 \%\end{array}$ & $\begin{array}{l}17 \\
56.7 \%\end{array}$ & .291 \\
\hline \multicolumn{3}{|l|}{ Education status of participant association disrespect } & \multirow{6}{*}{.049} \\
\hline $\begin{array}{l}\text { Not educated } \\
\% \text { within the education status of the participant }\end{array}$ & \begin{tabular}{|l|l|}
13 \\
$59.1 \%$
\end{tabular} & $\begin{array}{l}9 \\
40.9 \%\end{array}$ & \\
\hline $\begin{array}{l}\text { Primary } \\
\% \text { within the education status of the participant }\end{array}$ & $\begin{array}{l}21 \\
56.8 \%\end{array}$ & $\begin{array}{l}16 \\
43.2 \%\end{array}$ & \\
\hline $\begin{array}{l}\text { Middle } \\
\% \text { within the education status of the participant }\end{array}$ & $\begin{array}{l}16 \\
50.0 \%\end{array}$ & $\begin{array}{l}16 \\
50.0 \%\end{array}$ & \\
\hline $\begin{array}{l}\text { Matric } \\
\% \text { within the education status of the participant }\end{array}$ & $\begin{array}{l}2 \\
33.3 \% \\
\end{array}$ & $\begin{array}{l}4 \\
66.7 \%\end{array}$ & \\
\hline $\begin{array}{l}>\text { Matric } \\
\% \text { within the education status of the participant }\end{array}$ & $\begin{array}{l}0 \\
.0 \%\end{array}$ & $\begin{array}{l}3 \\
100.0 \%\end{array}$ & \\
\hline \multicolumn{3}{|l|}{ Average household income observed with disrespect } & \multirow{4}{*}{.037} \\
\hline$<10,000$ & 21 & 21.0 & \\
\hline $11000-15000$ & 61 & 61.0 & \\
\hline $16000-20000$ & 18 & 18.0 & \\
\hline \multicolumn{3}{|l|}{ Length of stay in Hospital predicted with disrespect } & \multirow{3}{*}{.188} \\
\hline$<12$ hours & 70 & 70.0 & \\
\hline$>12$ hours & 30 & 30.0 & \\
\hline
\end{tabular}

\section{Discussion}

Respectful maternity care is crucial components to decrease the maternal mortality ratio in the country and increase the rate of hospital-based delivery, if implemented completely. This study explored the proportion of women who faced different forms of disrespect during delivery in JPMC Karachi to using Quantitive and qualitative methods. This study fills the gap of trust between clients and health professionals, and the perceptions of women are regarding respectful delivery and practices at health facility centre. Disrespect and abuse in hospital-based childbirth habitually acts as a restraint to current and/or future consumption of facility-based childbirth care services. Several studies show up the correlation between disrespectful and abusive hospital-based childbirth care as expressed by women users and a choice by mother's users not to use facility based delivery services. These outcomes may be seen as different characteristic of users' trust in the health care delivery system. There are many previous studies it is mentioned that such actions is relatively common these kind of experiences suggest that disrespectful and abusive treatment during childbirth may be an important prevention to facility delivery. Disrespectful and abusive (D\&A) care is the massive in the Labor room as compare of other department in the hospital; and it makes the clients uncomfortable to talk about their genuine issues. "Our study fills the gap of trust between clients and health professionals, and the perceptions of women are regarding respectful delivery and practices at health facility center. In this study there was no any significant association found between age, education, household income and length of stay in hospital with disrespect. Intrapartum childbirth and Labor is the most important part that is vulnerable moment for pregnant mothers and they necessitate for attention and care is very essential. It is nevertheless natural that women attach enormous value to the take care they obtain during delivery time. Their satisfaction hinge upon timely and women's expectation are 'good' quality care. Many members of community were reluctant to trust them for providing for childbirth and delivery (10).

Most of the participants left them uncover and alone after delivery moreover no drapes and coverage were used during delivery in the study area, fewer clients report that none was available in the room when their baby was delivered after calling the doctors and nurses then they come. Sometimes health care professional use forcible pressure on the abdomen to push out the baby if cannot push out over the time they usually slapped on legs and physical abuse like Hit, also pinch as well during episiotomy procedure and their behavior usually uncooperative and shout on the clients. Our practices suggest that care designers should constantly consider all the appropriate sources of evidence, together with patient needs and necessities and professional harmony (12). Most important point in the study are non consented care and non dignified care in which majority of service provider do not introduce themselves. Thus women have no idea who is conducting their delivery as well as there is no information regarding the progress of labor, and condition of the newborn baby. They even never get permission before any procedure during labor. In this study there is mention that scrutiny and synthesis of bottlenecks and solutions for three intervention areas (SBA, BEmOC, CEmOC) related to the prerequisite of 
quality crucial care during labor and childbirth. we have originated that extensive term investment and planning to make stronger health systems especially human resources has been deficient from national and world wide responses (8).

Disrespectful and obnoxious treatment during child delivery was associated with considerably lower satisfaction with the child birth experience, perceived quality of care and assessment for delivery,-There are many previous studies reporting kind of experiences that suggest that disrespectful and abusive treatment during childbirth.As such, this sort of treatment may be one of the rationales for the underutilization of health facility delivery services still when women's delivery is free and facilities relatively abundant in Tanzania (11). Uncooperative attitudes of health care professionals can show the way to women being less enthusiastic to access care, attending later on for antenatal care and later when in labor (12). The SBA will always have to oversee and take the show the way in the provision of maternity care. They are the majority appropriate attendants who are qualified to recognize when a child birth is not moving ahead normally and will make out when and how to refer to causality obstetric care (13). Maternal and newborn health specialist improved the content exposure as well as the significance of items, which identified proportions to local perspective and addressed features validity and content legitimacy of the scale. The observed reliability has fallen in the variety of acceptable inner consistency described (14). Disrespect and abuse in hospital-based childbirth habitually acts as a restraint to current and/or future consumption of facility-based childbirth care services. Several studies show up the correlation between disrespectful and abusive hospital-based childbirth care as expressed by women users and choices by mothers users not to use facility based delivery services (2).

\section{Conclusion}

Disrespect and physical abuse is universal barrier to utilize service of health care facility center. It is vital to enhance the communication skills of health care professional, to maintain their privacy, dignity, confidentiality and consented care which must abuse free and friendly care in all those who have interaction with reproductive and maternal health care.

\section{References}

1. Ali SA, Lakhani A, Jan R, Shahid S, Baig M, Adnan F. Enhancement of knowledge and skills of community midwives in Sindh, Pakistan. Journal of Asian Midwives (JAM). 2015;2(2):3656.

2. Bowser D, Hill K. Exploring evidence for disrespect and abuse in facility-based childbirth. Boston: USAID-TRAction Project, Harvard School of Public Health. 2010.

3. Flavia ana, d'oliveira p. Violence against women in health-care institutions: an emerging problem.
2009;1681-85.

4. World Health Organization, UNICEF. Trends in maternal mortality: 1990 to 2013: estimates by WHO, UNICEF, UNFPA, The World Bank and the United Nations Population Division: executive summary.

5. National institute of population studies 2016.

6. Mugweni E, Ehlers VJ, Roos JH. Factors contributing to low institutional deliveries in the Marondera district of Zimbabwe. Curationis. 2008;31(2):5-13.

7. McMahon SA, George AS, Chebet JJ, Mosha IH, Mpembeni RN, Winch PJ. Experiences of and responses to disrespectful maternity care and abuse during childbirth; a qualitative study with women and men in Morogoro Region, Tanzania. BMC pregnancy and childbirth. 2014;14(1):1.

8. Sharma G, Mathai M, Dickson KE, Weeks A, Hofmeyr GJ, Lavender T, Day LT, Mathews JE, Fawcus S, Simen-Kapeu A, de Bernis L. Quality care during labour and birth: a multi-country analysis of health system bottlenecks and potential solutions. BMC pregnancy and childbirth. 2015;15(2):1.

9. Reis V, Deller B, Catherine Carr CN, Smith J. Respectful Maternity Care. Maternal and Child Health Integrated Program (MCHIP), Washington, 2012.

10. Srivastava A, Avan BI, Rajbangshi P, Bhattacharyya S. Determinants of women's satisfaction with maternal health care: a review of literature from developing countries. BMC pregnancy and childbirth. 2015;15(1):97.

11. Kruk ME, Kujawski S, Mbaruku G, Ramsey K, Moyo W, Freedman LP. Disrespectful and abusive treatment during facility delivery in Tanzania: a facility and community survey. Health Policy and Planning. 2014.

12. Akbari F, Lameei A, Mohammad K, Small R, Arab M. Developing evidence-based maternity care in Iran: a quality improvement study. BMC pregnancy and childbirth. 2008;8(1):1.

13. Henderson J, Gao H, Redshaw M. Experiencing maternity care: the care received and perceptions of women from different ethnic groups. BMC pregnancy and childbirth. 2013;13(1):196.

14. Sapkota S, T Sayami J, Manadhar M, Erlandsson K. To achieve safe and respectful maternity care in tertiary level hospitals in Nepal, relatives are a valued addition to the provision of maternity care. Journal of Asian Midwives (JAM). 2015;1(2):30-3.

15. Sheferaw ED, Mengesha TZ, Wase SB. Development of a tool to measure women's perception of respectful maternity care in public health facilities. BMC pregnancy and childbirth. 2016;16(1):67. 